\title{
Cognitive Disorder
}

National Cancer Institute

\section{Source}

National Cancer Institute. Cognitive Disorder. NCI Thesaurus. Code C92196.

A category of psychiatric disorders which are characterized by a deficit in cognition or memory. 